\section{Mental imagery}

\section{John Krebs}

The Question of Animal Awareness. By D. R. Griffin, Pp. viii +135 . (Rockefeller University: New York, 1976.) $\$ 8.95$.

GRIFFIN's thesis is that animals experience mental images and therefore a primitive form of awareness. One could argue about the meaning of these words and their relationship to the more strictly human experiences of subjective emotions and self-awareness, both of which are specifically excluded from Griffin's definitiors. But since it is easy to see roughly what Griffin is getting at, I think such a philosophical argument is superfluous. Much of the book is filled with the 'evidence' for animal awareness, and although the style is clear and concise, I feel that Griffin makes an unnecessarily elaborate case: most behavioural biologists are quite ready to accept the idea that animals have mental images of events or objects in their environment.

Th main points of Griffin's thesis are as follows. First, he establishes, with a few examples-such as bats

\section{a revolution in the theory of gravitation \\ A NEW RELATION BETWEEN THE VELOCITY OF LIGHT and PLANETARY MOTIONS discovered by MORRIS REDMAN SPIVACK PART || of}

$$
\begin{aligned}
& \mathbf{G}= \frac{\mathbf{M m} \mathbf{c}}{\mathbf{r}^{2}} \quad \begin{array}{c}
\text { (A revision of } \\
\text { NEWTON'S LAW) }
\end{array} \\
& \text { (5th EDITION-JAN., 1977) }
\end{aligned}
$$

\section{Abstract:}

. GRAVITATION transfers energy from one body to another with the velocity of light. The relative intensity of the field controlling the orbit may therefore be expressed as a propor tion of the velocity of light depending on the radius between the bodies.

. In the case of the non-periodic advance (excess motion) of the perihelia of any planets - if the excess motion be known (as it is in the case of MERCURY), then dividing the excess motion by the observed mean orbital motion will give a PROPORTION of the RECIPROCAL of the velocity of light (as pure number) which can be obtained independenty when the nonperiodic advance is not known (for example in the case of MARS).

3. The MEAN MOTION when multiplied by the proportion of . The MEAN MOTION when multiplied " by thus ind epend ently he reciprocil of WAYS Give us the EXCESS MOTION - and vice versa as at (2) above.

4 . The METHOD of Obtaining the correct proportion of " $"$ 4. The METHOD of Obtaining the correct proportion of " $c$ " independently and directly from reiativistic principles is demonstrated herein.

5. A new relation between the velocity of light and planetary motions is thus established, which may be useful in soiving other problerns of illimitable range and most certainly lead to the discovery of other important relationships and equivalencies in relativity.

4pp.. unbound follo, litho, \&1 or \$2, by tea mall (in the ORIGINAL STAMPED BOARDS, 85 or $\$ 10$.)

\section{MORRIS REDMAN SPIVACK} Post Restant 12, UPSWLA, SWEDEM catching their prey by sonar and birds orientating by star compasses - that animals are rather more complex than might have been supposed 50 years ago. Especially remarkable are the linguistic abilities of chimpanzees and honey bees. Chimps, such as Washoe, can construct sentences in American Sign Language, showing that they understand a few rules of human language, and bees use an arbitrary communication system for encoding information about remote feeding places.

Griffin sees the complexity of animal language as important, because so much of man's mental experience is dependent on language. (As an aside, the chimp and bee examples are always quoted as evidence for the complexity of animal language: chimps one can understand, but bees seem to be an anomaly. Either they are an evolutionary freak, or we are waiting for more scientists of von Frisch's genius.) In fact, the complexity of animal language does not seem to be a crucial part of Griffin's thesis, since some of the clearer examples of mental imagery in animals-for example, 'searching images'-do not involve complex language.

Another line of evidence used by Griffin is neurophysiological. He revives the argument that the nervous system of man is only quantitatively different from that of animals, so products of the nervous system such as awareness should also differ only in quantity. This assumes, of course, that quantitative differences are not translated by thresholds into qualitative effects.

Finally, Griffin argues on evolution-

\section{Brain anatomy}

\section{J. Z. Young}

The Vertebrate Brain. By R. Pearson and L. Pearson. Pp. xi-744. (Academic: London and New York, 1976.) £23.

THE great expansion of interest in neuroscience in recent years has not been accompanied by an equivalent interest in comparative neurology. Microscopists and experimentors have indeed used neurones from very diverse animals, but few have tried to investigate their specific adaptive features in relation to the environment. Still fewer have tried to follow the course of evolution of the brain throughout the vertebrate phylum. The only comprehensive work on the subject is that of Kappers, Huber and Crosby written in 1936. The leading living expert in the field in Hans Kuhlenbeck, whose major work is still appearing. One looks therefore with excitement at a new book on The Vertebrate Brain. ary grounds that mental awareness has survival value in allowing an animal to anticipate and cope with complex problems, so it should be favoured in all animals by natural selection. Interestingly, Griffin does not use dreaming in animals as evidence for mental imagery, although all dog-watchers will agree that dogs dream about chasing the cat next door.

Whether or not they accept the individual steps in his argument (most of which are not new), most behavioural biologists will concur with Griffin's overall thesis. Equally, I feel that most will be disappointed with Griffin's answer to the "so what?" question. The test of the value of any scientific hypothesis is whether or not it generates new experiments, and it seems to me that the awareness hypothesis fails this test.

Griffin argues, by analogy with man, that the only way to find out about an animal's mental experiences, it to ask it directly, or indirectly, what is it thinking about. With Washoe this might be done through American Sign Language, with bees and birds through life-like dummies or models. If one leaves out the special case of Washoe and his clan, what it boils down to is a plea for more work on animal communication. This is an uncontroversial proposition, but if I try to think up experiments or observations to elucidate the meaning of, for example, the incredibly complex song of a skylark, is the hypothesis that larks have mental experiences going to help me?

John Krebs is Lecturer in Zoology at the Edward Grey Institute of Field Ornithology, University of Oxford, UK.

The authors' aim is to provide "a survey of the anatomical, biochemical and physiological aspects of the vertebrate brain". They believe that the development of the neurosciences "will probably prove as profound in their effects on man and his philosophies as did the concepts of nuclear physics during the 1930s or the 'molecular biologists' of the 1950s".

This may turn out to be so, but unfortunately the data that they have collected certainly do not provide a sufficient basis for such a revolution. The function of the nervous system is to process "information", but this word does not occur in the index, nor does "code" or "representation", or indeed "action potential," "electroencephalogram", or most of the terms of neurophysiology. We shall only be able to compare different brains when we have developed adequate ways of analysing how complex masses of nervous tissue process information.

What the present authors have done is to make a survey of some aspects 